\title{
A presença da filosofia e da ética no contexto profissional
}

Terezinha Azerêdo Rios

- Doutora em Educação pela Universidade de São Paulo (USP)

- Mestre em Filosofia da Educação pela Pontifícia Universidade Católica de São Paulo (PUC-SP)

- Graduada em Filosofia pela Universidade Federal de Minas Gerais (UFMG)

- Professora pesquisadora do Programa de Pós-Graduação em Educação da Universidade Nove de Julho (Uninove-SP)

- Autora dos livros Ética e competência; Compreender e ensinar - por uma docência da melhor qualidade; e Filosofia na escola - o prazer da reflexão (em co-autoria com Marcos Antonio Lorieri)

- Membro do Grupo de Pesquisas e Estudos sobre Formação de Professores (Gepefe), da Faculdade de Educação da USP

- Consultora em projetos de formação continuada de profissionais de diversas áreas

- te.rios@terra.com.br 


\section{Resumo}

Neste artigo, apresenta-se a tese de que há necessidade de trazer para o espaço das organizações e da prática dos profissionais que aí realizam seu trabalho a reflexão crítica que se dá no campo da filosofia. Também se apontam as diferentes dimensões da competência profissional, reconhecendo a ética como dimensão fundante do trabalho de boa qualidade.

PALAVRAS-CHAVE: REFLEXÃO FILOSÓFICA • ÉTICA • COMPETÊNCIA

\section{Abstract}

In this article we discuss the need to bring into the organizations' spaces and to the practice of the professionals that carry out their activities in them the critical reflection that occurs in the field of philosophy. We also point out the various dimensions of professional competence, acknowledging ethics as being an essential dimension of work conducted with good quality.

KEYWORDS: PHILOSOPHICAL REFLECTION • ETHICS • COMPETENCE

\section{Resumen}

Se presenta la tesis de que es necesario traer al espacio de las organizaciones y de la práctica de los profesionales que en ellas realizan su trabajo la reflexión crÍtica originada en el campo de la filosofía. Se señalan las diferentes dimensiones de la competencia profesional y se reconoce la ética como una dimensión fundamental del trabajo de buena calidad.

PALABRAS CLAVE: REFLEXIÓN FILOSÓFICA • ÉTICA • COMPETENCIA 
Toda ética digna deste nome parte da vida e se propõe a reforçá-la, a torná-la mais rica.

Fernando Savater

A ssim como em outras instâncias do social, constatamos hoje nas empresas uma preocupação com a presença da ética, tanto no seu contexto interno quanto nas relações que se estabelecem com a sociedade. Essa preocupação tem origem nos desafios contemporâneos para a construção ou para o reordenamento de sociedades em que a dignidade e a justiça estejam presentes, superando as desigualdades e a violência que têm marcado as relações humanas, sobretudo nas cidades.

É preciso, entretanto, estarmos atentos para o fato de que, muitas vezes, o apelo à ética se faz apenas no discurso e está ausente na prática das relações cotidianas. Daí a necessidade de fazermos constantemente o exercício da crítica, para identificar os limites e explorar as possibilidades de uma efetiva presença da ética.

O exercício crítico que se propõe aqui é o da reflexão filosófica. A ética é a face da filosofia que se debruça sobre os valores que orientam nossas ações e relações na sociedade. Trago, portanto, um convite para que façamos uma reflexão "à moda da filosofia”.

\section{Refletir "à moda da filosofia"}

Quando se faz esse convite, podem-se encontrar reações diversas. "Não me venha com filosofias!” é uma das mais freqüentes. Muitas pessoas julgam que a filosofia é algo que não tem relação com a realidade, próprio de quem sempre vive "com a cabeça nas nuvens", distante da vida cotidiana. E há, por outro lado, aqueles que pensam que a filosofia é uma espécie de "sabedoria prática", a que se recorre para "levar a vida” sem problemas. Como são muitas as idéias, é importante esclarecer do que falo quando faço meu convite.

\section{Comecemos pelo que se entende por refletir}

A reflexão é um retorno, uma "volta do pensamento" para um determinado objeto um fato, uma vivência, uma idéia - com a intenção de olhá-lo de um jeito diferente do que se fazia antes, tomando-se uma distância, submetendo-o a uma análise detalhada. Pensamos sempre, mas nem sempre refletimos. Nossa reflexão é provocada pelo que denominamos problemas, obstáculos com os quais nos deparamos em nossa vida, em nossas relações, e que temos necessidade de superar.

Um problema não se caracteriza pela dificuldade ou pela complexidade, mas, sim, pelo caráter de necessidade com que temos de enfrentá-lo e de impossibilidade imediata 
que temos de fazer isso. Uma pergunta cuja resposta não sabemos só se converte em um problema se temos efetivamente necessidade de respondê-la imediatamente e não temos condição de fazê-lo. Uma porta trancada só se converte em problema se necessitamos abri-la naquele momento e não temos a chave.

A reflexão pode não nos trazer um conhecimento novo, mas nos auxilia a ver de um jeito novo o já conhecido, a retomar o caminho para seguir adiante com um olhar alargado.

\section{E que tipo de reflexão é a que nos propõe a filosofia?}

No conceito de filosofia, já está contido o de reflexão. A filosofia se apresenta como uma busca constante e amorosa de um saber cada vez maior. É assim que ela foi definida por Pitágoras, no século VI a.C.: como amizade (philia) à sabedoria (sophia), entendida esta como saber de todas as coisas, saber inteiro.

Para buscar a sabedoria, é preciso não se contentar com as opiniões, com o conhecimento do senso comum, mas refletir, voltar-se sobre ele, assumir uma atitude crítica, no sentido de ver com clareza, profundidade e abrangência a realidade e as nossas relações com ela e com os outros.

Ver claro, para evitar os elementos que prejudicam nosso olhar, evitar as armadilhas que se acham instaladas em nós e em torno de nós, nas situações que vivenciamos.

Ver fundo, não se contentando com a superficialidade, procurando ir às raízes, buscando os fundamentos do que se investiga.

Ver largo, na totalidade, o que implica levar em consideração o contexto no qual se insere o objeto, os elementos que o determinam e os diversos ângulos sob os quais se apresenta.

Para observar esses múltiplos ângulos, é necessário colocar-se em diversos pontos de vista. Temos o vício de julgar que nosso ponto de vista - que é sempre a vista de um ponto, como afirma Leonardo Boff (1997, p. 9) -, se não é o único, é o melhor. A crítica nos faz reconhecer que existem outros pontos de vista, que a contradição é uma característica fundamental da realidade, que é multifacetada e exige um esforço de abrangência para seu conhecimento.

Costumamos pensar na crítica, no nível do senso comum, como um gesto de "falar mal”, de indicar os aspectos negativos de uma pessoa ou de uma atitude. Não é assim que a estamos considerando aqui. Quando assumimos uma atitude crítica, procuramos olhar de maneira abrangente para ver os aspectos bons e maus. A crítica nos permite "iluminar" o que estamos investigando, no sentido de aprimorar o que está bom e procurar superar o que não está. Na atitude crítica, encontra-se um questionamento, uma indagação, um desejo de ampliar o nosso conhecimento. 
O esforço filosófico, como exercício de crítica, implica uma atitude humilde e corajosa.

A atitude crítica é humilde, reconhecendo os limites que existem nas situações vivenciadas. Só quem reconhece que não sabe, que há ainda muito por ser conhecido, empreende uma busca para ampliar seu saber.

E é corajosa, porque é sempre um gesto de provocação e, por isso, sempre tende a enfrentar perigos, ameaças. O olhar crítico desvenda, aponta coisas que podem incomodar, desinstalar, exigir mudanças para as quais muitas vezes não se está preparado.

As idéias de reflexão e de crítica não se ligam, entretanto, apenas ao conhecimento filosófico. Vamos encontrá-las também no campo do conhecimento científico - a ciência tem sido definida justamente como um tipo de conhecimento crítico.

É importante, então, esclarecer o que distingue a atitude filosófica da atitude científica. A ciência define sempre um objeto específico para sua investigação, faz sempre um recorte na realidade, enquanto a filosofia se volta para a multiplicidade dos objetos que compõem o real. Além de uma distinção em relação ao objeto, a filosofia propõe uma distinção em relação ao objetivo daqueles saberes: enquanto a ciência visa explicar a realidade, descrevê-la, analisá-la, a intenção da filosofia é compreender.

O esforço de compreensão, próprio da filosofia, procura ir além da explicação e olhar a realidade em busca de sua significação, de seu sentido, de seu valor. Quando, por exemplo, fazemos uma reflexão "à moda da filosofia" sobre nosso trabalho, estamos perguntando: de que vale esse trabalho; que significado têm nossas ações no contexto de nossas organizações?

Como busca amorosa do saber (philo-sophia), o gesto filosófico abriga uma articulação entre uma dimensão epistemológica e uma dimensão afetiva da relação dos homens com o mundo e com os outros, uma idéia de prender-com, de apropriar-se junto, reveladora de um "coração compreensivo", e não a mera intelecção ou o mero sentimento, como aponta Arendt (1993, p. 52). Guarda, ainda, como busca, um sentido de movimento, de caminhar constante. E se o saber pretendido é um saber inteiro, faz-se necessária uma atitude de admiração diante do conhecido, de surpresa diante do habitual, a fim de conhecer mais e melhor.

Kant afirmava que não se aprende (ou se ensina) filosofia, mas, sim, que se aprende (ou se ensina) a filosofar. Com isso, aquele filósofo queria chamar atenção para o fato de que é importante caracterizar o gesto filosófico mais do que as teorias dos filósofos que dele resultam.

Será que as teorias, então, não merecem que reflitamos sobre elas? Não interpretemos assim a afirmação kantiana. É muito importante conhecer as teorias, pois, desse modo, verificaremos como elas estão presentes no modo de pensar e de agir dos indivíduos e das sociedades no decorrer da história. Quando vemos a importância 
exagerada dada à técnica no interior de nossas organizações, nem sempre sabemos que isso representa uma tendência, o tecnicismo, que resulta de uma concepção filosófica, o positivismo, segundo o qual o conhecimento científico deve ser o modelo de todo o pensamento.

O gesto que caracteriza a reflexão filosófica é o de perguntar. E que tipo de perguntas são as filosóficas?

O filósofo indaga sobre o mundo: que realidade é essa que nos constitui e que, ao mesmo tempo, transformamos? O que existe efetivamente? O que é o real? Essas indagações nos levam ao terreno da ontologia.

O filósofo pergunta pelo conhecimento - o que é conhecer; como se dá o conhecimento; como se distinguem os tipos de conhecimento? Quando fazemos essas perguntas, estamos no campo da gnoseologia, da teoria do conhecimento.

O filósofo pergunta pelas formas do conhecimento, pelos caminhos que conduzem a um conhecimento seguro e verdadeiro. Essas perguntas se dão no espaço da lógica.

O filósofo pergunta pelo sentido da presença do ser humano e da criação da cultura, da constituição da sociedade. Aí se encontram a antropologia filosófica e a filosofia política.

O filósofo também pergunta pelos valores. Quando ele se volta para valores que se referem à criação artística, estamos no terreno da estética; quando se enfocam os valores que dizem respeito à conduta humana, estamos no terreno da ética. (LORIERI e RIOS, 2008). É ela que vai nos interessar particularmente aqui.

Fora do espaço da filosofia, muitos perguntam: e para que serve fazer essas perguntas; qual é a utilidade da filosofia? Marilena Chauí (1994, p. 18) tem uma resposta para nós:

"Se abandonar a ingenuidade e os preconceitos do senso comum for útil; se não se deixar levar pela submissão às idéias dominantes e aos poderes estabelecidos for útil; se buscar compreender a significação do mundo, da cultura, da história for útil; se conhecer o sentido das criações humanas nas artes, nas ciências e na politica for útil; se dar a cada um de nós e à nossa sociedade meios para serem conscientes de si e de suas ações numa prática que deseja a liberdade e a felicidade para todos for útil, então podemos dizer que a Filosofia é o mais útil de todos os saberes de que os seres humanos são capazes."

Já no século IV a.C., Epicuro dizia que "quem afirma que a hora de dedicar-se à filosofia ainda não chegou, ou que ela já passou, é como se dissesse que ainda não chegou ou que já passou a hora de ser feliz".

Um convite à filosofia tem, portanto, a intenção de explorar as características da atitude filosófica, com a intenção de articulá-la com outros saberes, para construir uma história mais fecunda e uma vida mais plena dos indivíduos na sociedade. 
A filosofia é sempre filosofia de, olhar voltado (re-flexão) sobre os problemas que nos desafiam. Se ela se volta para o espaço do trabalho, das organizações, ela aparecerá como filosofia da administração. Como tal, ela buscará, ao lado de outras perspectivas de conhecimento, compreender o fenômeno organizacional em todas as suas facetas, procurará olhar criticamente a tarefa do administrador, do gestor, da instituição, da empresa como instância social e política, perguntará pelo sentido das ações e relações dos indivíduos que as compõem e poderá auxiliar nas decisões que se tomam com a intenção de transformá-las.

É a filosofia, na sua feição de ética, que procurará apontar os princípios que devem nortear as ações e que sustentarão a qualidade da organização e a competência dos profissionais. Se nos voltarmos para a história dos indivíduos que se destacam ou destacaram como líderes ou para a história das organizações bem sucedidas, vamos encontrar, sem dúvida, a presença do questionamento reflexivo e crítico, próprio da filosofia, como estimulador dos processos na direção do objetivo fundamental que é a construção da sociedade justa e solidária, do bem comum.

\section{De que falamos quando falamos em ética?}

Falar em ética pode remeter à abordagem de um tema que "está na moda". A ética está em todas as bocas - tanto no discurso de quem protesta contra a violência, como no dos que cometem as ações violentas; tanto no daqueles que denunciam a corrupção, como no dos corruptos. Freqüentemente, a palavra ética tem sido "usada em vão", destituída de seu significado autêntico ou histórico. Temos, portanto, que esclarecer o que queremos dizer quando falamos em ética. E, para isso, devemos fazer uma distinção entre os conceitos de ética e moral.

No cotidiano, os termos ética e moral são usados, indistintamente, para indicar a presença de valores que se relacionam com o bem e o mal, no comportamento dos indivíduos. Embora as palavras que os designam tenham a mesma origem etimológica, os conceitos incorporaram, em seu percurso histórico, significações diferenciadas. No âmbito da filosofia, hoje, faz-se uma distinção entre eles.

A moral é definida como conjunto de valores, de princípios, de regras que norteiam o comportamento humano. No espaço da moralidade, aprovamos ou reprovamos o comportamento dos indivíduos e o designamos como certo ou errado, correto ou incorreto. Há sempre uma expectativa da sociedade em relação ao desempenho dos papéis e nossa conduta é aceita ou rejeitada à medida que corresponda ou não a essa expectativa.

A ética é a reflexão crítica sobre a moralidade. Não tem a pretensão de definir normas, mas indicar princípios. Quando fazemos uma reflexão ética, estamos nos perguntando sobre a consistência e a coerência dos valores que norteiam nossas ações de caráter moral; buscamos sua fundamentação para que as ações tenham significado autêntico em nossas relações sociais. A ética reflete sobre os valores que comandam a ação e a 
fazem ir além do nível imediato da situação, criando um horizonte em cuja direção a ação se projeta, na busca de seu dever ser (PESSANHA, 1993, p. 3).

Cabe à ética problematizar, perguntar o porquê das ações e dos juízos morais. No terreno da moral, os critérios utilizados para conduzir a ação são os mesmos que se usam para os juízos sobre a ação: eles estão sempre ligados a interesses específicos de cada organização social. No plano da ética, estamos na perspectiva de um juízo crítico, próprio da filosofia, que quer compreender, quer buscar o sentido da ação. Entre a moral e a ética, há um constante movimento, que vai da ação para a reflexão sobre o seu sentido - os seus fundamentos -, e, da reflexão, retorna à ação, revigorada e transformada.

As ações morais têm sua origem nos costumes de cada sociedade. Esses costumes estão fundados em valores - o que é costumeiro é confundido, muito freqüentemente, com o que é bom. E, então, porque algumas ações reprováveis tornam-se costumeiras em algumas instâncias sociais, as pessoas são levadas a afirmar que "já que é costumeiro, não é mau".

Isso é o que acontece muitas vezes nas organizações - recorre-se a determinadas formas de comportamento já "consagradas", sem perguntar por sua consistência ou coerência. São "costumeiros" os atrasos para as reuniões, o favorecimento aos que "obedecem sem criar problemas", logo... serão bons?

É para evitar equívocos dessa natureza que recorremos à ética. Diferente da moral, que tem um caráter normativo, a ética tem um caráter reflexivo. É com base em seus princípios - o respeito, a justiça, a solidariedade - que as ações morais podem ser julgadas.

Vale fazer a distinção, pois a moral está sempre presente nas ações e relações dos indivíduos e grupos - não há sociedade que não estabeleça uma forma de conduta para seus membros. Temos uma conduta moral quando nos posicionamos em relação às imposições que nos traz a sociedade, dizendo sim ou não, obedecendo ou desobedecendo.

Somos responsáveis - respondemos e nos comprometemos. O compromisso é próprio dos seres humanos - só eles podem prometer, com-prometer. E cumprir a promessa. Ou não cumpri-la. Agimos moralmente. Mas nem sempre realizamos uma reflexão ética. Nem sempre buscamos verificar a consistência dos valores, os fundamentos das ações. É disso que temos sentido falta nas sociedades contemporâneas.

No contexto das organizações, que aqui nos interessa especificamente, a ética tem o papel de indagar se as ações e relações profissionais estão fundadas em princípios que levam à promoção do bem comum, da dignidade humana, da vida feliz.

\section{0 bem comum: núcleo da ética}

No horizonte da reflexão ética, aponta-se a realização do bem comum, a efetivação da cidadania democrática. O bem comum é bem coletivo, bem público. O público é "o 
pertencente ou destinado à coletividade, o que é de uso de todos, aberto a quaisquer pessoas" (FERREIRA, 1975, p. 1165). É, então, o campo da democracia, como espaço de realização de direitos civis - liberdade de ir e vir, de pensamento e fé, de propriedade; direitos sociais - de bem-estar econômico, de segurança; e de direitos políticos — de participação no exercício do poder — de todos os homens e mulheres.

Ao entender o poder como possibilidade de atuação, de interferência e determinação de rumos na sociedade, verifica-se que, se há o desejo de construir uma sociedade realmente democrática, é necessário que todas as instituições se mobilizem para promover, no seu contexto, o espaço para o desenvolvimento da cidadania.

A cidadania é uma condição construída historicamente. Ser cidadão é participar de uma sociedade, tendo direito a ter direitos, bem como construir novos direitos e rever os já existentes. Participar é ser parte e fazer parte — com seu fazer, sua interferência criativa - na construção da sociedade: nos espaços públicos e privados, os indivíduos configuram seu ser, sua especificidade, sua marca humana.

No mundo contemporâneo, cada vez mais, as organizações são solicitadas a assumir um compromisso com a promoção dessa cidadania, do bem-estar e da satisfação dos indivíduos e grupos na sociedade. Elas têm um papel fundamental na produção de boas condições de trabalho e práticas de responsabilidade social, riquezas que elevam o nível e a qualidade de vida de um país. Se essas organizações estão efetivamente voltadas para a promoção e o desenvolvimento de ações que vão ao encontro de necessidades concretas da comunidade da qual fazem parte, elas não podem deixar de tomar como referência os princípios da ética e ter como horizonte o bem comum.

O outro nome do bem comum é felicidade, que não deve ser confundida com algo romântico, e, sim, tem a ver com a concretização da vida, com a realização - sempre buscada - do ser humano, e que é algo que não se experimenta apenas individualmente, mas que ganha seu sentido mais pleno na coletividade.

Colaborar na construção da felicidade, no seu mais pleno sentido, é a tarefa que está apontada como propósito das organizações que se apresentam como cidadãs.

\section{A ética como dimensão da competência profissional}

A competência guarda o sentido de saber fazer bem o dever. Na verdade, ela se refere sempre a um fazer que requer um conjunto de saberes e implica um posicionamento diante daquilo que se apresenta como desejável e necessário. É importante considerar-se o saber, o fazer e o dever como elementos historicamente situados, construídos pelos sujeitos em sua praxis.

Na competência profissional articulam-se:

- Uma dimensão técnica, que diz respeito ao domínio de conhecimentos na 
área em que se desenvolve o trabalho e à habilidade na utilização e partilha desses conhecimentos.

- Uma dimensão estética, que está relacionada à sensibilidade dos indivíduos na percepção das relações intersubjetivas que se dão em seu trabalho. Não há possibilidade de falar de um bom profissional quando na sua prática não está inserida nenhuma perspectiva de sensibilidade, de afetividade - afetividade no sentido de se deixar afetar pelo trabalho, sensível às manifestações que existem no seu relacionamento com a sua prática.

- Uma dimensão política, na medida em que esse trabalho é desenvolvido num contexto social que o determina e diante do qual se tem que fazer opções. Ser político, afirma Heller (1982, p. 55), é tomar partido, não necessariamente ser de um partido, e, sim, não ficar indiferente diante das alternativas sociais.

- Uma dimensão ética, que se aponta como dimensão fundante da competência, uma vez que a técnica, a estética e a política ganharão seu significado pleno quando, além de se apoiarem em fundamentos próprios de sua natureza, se guiarem pelos princípios éticos - o respeito, a justiça, a solidariedade.

A competência se apresenta, então, como uma totalidade que abriga em seu interior uma pluralidade de propriedades, um conjunto de qualidades de caráter positivo, fundadas no bem comum, na realização dos direitos do coletivo de uma sociedade (RIOS, 2008).

A idéia de considerar a competência como uma totalidade não implica uma cristalização ou o enrijecimento num modelo, mas indica a impossibilidade de se mencionar uma competência parcial, representada apenas por alguma de suas dimensões. Por isso é que não faço referência a uma "competência técnica", uma "competência política" ou uma "competência ética" - não se trata de três competências, e, sim, de três componentes de uma competência. O conjunto de propriedades, de caráter técnico, estético, ético e político é que define a competência.

Minha tese é de que um trabalho competente, de boa qualidade, é um trabalho que faz bem, isto é, que fazemos bem, de todos aqueles pontos de vista que mencionei, e que faz bem para nós e para aqueles que estão envolvidos em nossas ações.

\section{Competência e utopia}

Deve-se assinalar, ainda, que competência não é algo isolado, que depende apenas das características pessoais dos indivíduos. Nenhum profissional é competente sozinho - a qualidade de seu trabalho não depende apenas dele, define-se na relação com os outros. As condições para o trabalho competente de um profissional dizem respeito a esse profissional, a suas características individuais e ao seu empenho no desenvolvimento do trabalho, mas têm a ver também com as condições do contexto e daqueles com quem ele se relaciona nesse contexto (RIOS, 2007, p. 79).

Mais ainda: sendo um processo, tendo um caráter histórico, a competência não é algo 
pronto, que se adquire de uma vez por todas. No quadro das contradições que constituem sua vida e seu trabalho na sociedade é que se vai configurando/concretizando o ofício de cada profissional. Vamos nos tornando competentes, tendo oportunidade de modificar nossa prática, nossas concepções teóricas, nossas relações de trabalho.

Por isso, ainda não somos os profissionais que queremos e necessitamos ser. A competência se coloca para nós como um ideal. Esse ideal - utopia - não é, entretanto, uma quimera, uma vez que descobrimos no real, no presente, em nós e nas circunstâncias, as possibilidades de concretizá-lo. O profissional, no exercício competente de seu ofício, com o espírito alerta da crítica para a construção conjunta da sociedade de/ para todos, tem o desafio de se pôr a caminho, na direção daquele ideal.

Vejo com satisfação que têm crescido o interesse e a preocupação com as questões éticas no interior das organizações. São vários os programas de formação de executivos, de lideranças políticas e empresariais que incluem um espaço específico dedicado à reflexão sobre a ética. Pode-se perceber que os participantes desses programas se envolvem nas discussões e procuram levá-las adiante em suas organizações.

É importante partir dos problemas que se encontram no cotidiano dos profissionais e procurar olhá-los de diversos pontos de vista, buscando articulá-los com o contexto social mais amplo e permanecendo alerta para as transformações que são necessárias.

É preciso lembrar que ainda há algumas resistências - o exercício de reflexão ainda não é algo habitual, num mundo em que se anda em busca de receitas fáceis e imediatas! Mas é num esforço sério e coletivo que está a possibilidade de caminhar na direção de uma sociedade mais democrática e solidária.

\section{Referências}

ARENDT, Hannah. A dignidade da política. Rio de Janeiro: Relume-Dumará, 1993.

BOFF, Leonardo. A águia e a galinha: uma metáfora da condição humana. $3^{\text {a }}$ ed. Petrópolis: Vozes, 1997. CHAUI, Marilena. Convite à filosofia. São Paulo: Ática, 1994.

FERREIRA, Aurélio B. H. Novo dicionário da língua portuguesa. Rio de Janeiro: Nova Fronteira, 1975. HELLER, Agnes. Para mudar a vida - felicidade, liberdade e democracia. São Paulo: Brasiliense, 1982. LORIERI, Marcos A. e RIOS, Terezinha A. Filosofia na escola - o prazer da reflexão. $2^{\mathrm{a}}$ ed. São Paulo: Moderna, 2008. PESSANHA, José Américo. A ética do cotidiano. Perspectiva Universitária, junho/1993, p. 3. (entrevista). RIOS, Terezinha A. Ética e competência. 17 ed. São Paulo: Cortez, 2007. Compreender e ensinar - por uma docência da melhor qualidade. $7^{\text {a }}$ ed. São Paulo: Cortez, 2008. SAVATER, F. Ética para meu filho. São Paulo: Martins Fontes, 1992. 